\title{
LABORATÓRIO DE DESIGN, COCRIAÇÃO E SUSTENTABILIDADE: uma iniciativa no ensino de Design
}

\author{
MOUCHREK, Najla; Mestre em Design, Inovação e Sustentabilidade; \\ Universidade do Estado de Minas Gerais; najlammouchrek@gmail.com \\ KRUCKEN, Lia; Doutora, Professora do Programa de Pós Graduação em Design, \\ Inovação e Sustentabilidade; Universidade do Estado de Minas Gerais; \\ lia.krucken@pq.cnpq.br
}

\begin{abstract}
Resumo: Este trabalho apresenta o Laboratório de Design, Cocriação e Sustentabilidade, desenvolvido no contexto do curso de graduação da Escola de Design da Universidade do Estado de Minas Gerais. Seu propósito é investigar estratégias de Design para promover a cultura de sustentabilidade entre jovens. A metodologia envolve o desenvolvimento de abordagem participativa em Design, contando com análise, compreensão de contexto e proposição de estratégias a partir das competências de Design. São apresentados os principais resultados da iniciativa, que reforçam a importância de incluir na formação de jovens profissionais em Design o desenvolvimento de competências em sustentabilidade, estimulando a reflexão crítica e a capacidade de implementar soluções inovadoras. Destaca-se o potencial das abordagens de cocriação em Design como iniciativas promissoras na construção de contextos para transformação no campo da promoção da cultura de sustentabilidade, especialmente no âmbito do ensino de Design.
\end{abstract}

Palavras-chave: Design para sustentabilidade, Inovação Social, Ensino de Design, Cocriação.

Abstract: This paper presents the Laboratory of Design, Co-creation and Sustainability, developed in the context of the undergraduate program of the School of Design at the University of the State of Minas Gerais. Its purpose is to investigate design strategies to promote a culture of sustainability among young people. The methodology involves the development of a participatory design approach, relying on analysis, understanding of context and proposing strategies from the skills of Design. The main results of the initiative are presented. They reinforce the importance of including in the training of young professionals in Design: development skills in sustainability, encouraging critical reflection and ability to implement innovative solutions. We highlight the potential of co- 
creation in Design approaches as promising initiatives in building contexts for transformation in the field of promoting a culture of sustainability, especially in the context of teaching Design.

Keywords: Design for Sustainability, Social Innovation, Teaching Design, Cocreation

\title{
1. INTRODUÇÃO
}

No contexto atual, destaca-se a importância de investir na promoção de uma cultura de sustentabilidade entre os jovens, desenvolvendo processos e estratégias de interação e promovendo a construção de contextos para transformação. É especialmente em relação às novas gerações que a transição rumo a modos de vida mais saudáveis, integrados e sustentáveis mostra-se fundamental.

A área de Design constitui um potencial campo de inovação criativa e suporte para iniciativas promissoras de promoção de sustentabilidade, oferecendo competências e habilidades, uma metodologia projetual e um olhar diferenciado.

O objetivo deste trabalho é investigar estratégias de Design para transformação de contextos e promoção da cultura de sustentabilidade entre jovens. O foco é desenvolver e aplicar abordagens participativas, especialmente no âmbito do ensino de Design, direcionadas à promoção de sustentabilidade junto àquele público.

No contexto da formação de jovens profissionais em Design, considera-se a centralidade de desenvolver competências em sustentabilidade, estimular 0 pensamento crítico e a capacidade de propor e implementar estratégias inovadoras nesse campo. Esse processo visa contribuir para um novo delineamento do profissional de Design, apto a atuar de forma criativa e efetiva na busca de soluções para as questões complexas que se apresentam na atualidade.

Neste sentido apresenta-se o Laboratório de Design, Cocriação e Sustentabilidade, uma iniciativa desenvolvida no contexto do curso de graduação em Design da Universidade do Estado de Minas Gerais. Primeiramente, expõem-se o referencial teórico e os procedimentos e métodos adotados. A seguir, descreve-se a iniciativa e os resultados obtidos e apresentam-se as considerações finais do trabalho, com o propósito de contribuir para o avanço na reflexão sobre o tema e para a proposição de caminhos e ideias para a compreensão da questão a partir de pesquisa, análises e experimentação conduzidas e orientadas pelo Design.

\section{REFERENCIAL TEÓRICO}

\subsection{O papel do Design frente aos desafios contemporâneos}

\begin{abstract}
Historicamente, a tarefa do Design era mais simples do que é hoje, e a responsabilidade do designer era mais fácil de definir. [...] Agora, face à crescente complexidade, designers tem que pensar mais profundamente sobre o futuro e seu papel em construí-lo no presente. (MARGOLIN, 2007, p.14)
\end{abstract}

A revisão bibliográfica traça uma reflexão sobre a natureza do Design e seu papel frente aos desafios contemporâneos, investigando sua potencialidade como um 
modo alternativo de intervenção, para abordar e enfrentar os complexos desafios contemporâneos.

Podemos associar vários significados e interpretações ao conceito de Design. A princípio, a palavra refere-se tanto a desenho, quanto a projeto e planejamento. $O$ Design é um processo dinâmico - o ato de pensar, planejar e divisar cursos de ação com um propósito específico. Podemos dizer que o designer é um pensador cujo trabalho é mover-se do pensamento para a ação (FRIEDMAN, 2000, p. 10) Em sua capacidade intrínseca de fusão entre a ideia e o visível, uma dupla qualidade de representação e percepção ativa, a ação de Design constitui o ato de fazer vir, de "trazer algo da não-presença à presença" (MOURA, 2005, p.73-74). Ao agregar valores semânticos aos objetos e tomar consciência das suas possibilidades comunicativas; o Design é capaz de construir algo, distingui-lo através de um signo, dar-lhe significado; designar as relações que ele estabelece; construir o sentido das coisas e das experiências (FRANZATO, 2010, p.89-90).

Assim, podemos abordar o Design em suas diversas dimensões, entre as quais destacamos: a) enquanto um esforço consciente do sujeito para estabelecer uma ordem significativa para as coisas e objetos que o cercam (McCARTHY e GRENVILLE apud FONTOURA, 2002, p.209); b) enquanto processo e conjunto de atividades projetuais e criativas; $c$ ) enquanto agente ativo para solução de problemas, através do planejamento e implementação de ações para "transformar uma situação existente em uma outra desejada" (SIMON, 1982, p. 129); d) enquanto agente de criação e recriação de sentido aos objetos e às experiências (FRANZATO, 2010, p.89-90); e) enquanto agente de mediação entre diversos atores, transversal por natureza, que atua facilitando e apoiando o desenvolvimento de inovações (KRUCKEN, 2009, p.45).

No contexto em que este trabalho se insere, exploram-se as possibilidades de intervenção diferenciadas junto à solução de questões contemporâneas como a transição rumo à sustentabilidade, a partir das competências e formas de pensamento e ação específicas do Design.

\subsection{Design e promoção da cultura de sustentabilidade}

A criatividade e as habilidades de Design são elementos efetivamente necessários para mover um processo de inovação social e tecnológica de tal magnitude como requer a transição rumo à sustentabilidade (MANZINI, 2008, p. 16)

$\mathrm{Na}$ transição em direção a uma cultura e um estilo de vida sustentáveis, emergem potencialidades e interfaces de ação do Design, indicando que conceitos e ferramentas de Design podem oferecer suporte e caminhos criativos para práticas inovadoras.

Os autores apontam que o Design pode ser um poderoso catalisador neste campo, revelando-se uma eficaz metodologia de intervenção (MANZINI, 2008b, n.p.). Observa-se também que características próprias do Design podem contribuir para solucionar as questões do nosso tempo: riqueza interpretativa e habilidade visionária (KRUCKEN, 2008, p.23), bem como habilidades de pensar sistemicamente e inventividade de linguagem (CARDOSO, 2012, p.244-245).

No sentido prático, o Design pode participar: 
a. Propondo soluções plurais e projetando novos cenários (KRUCKEN, 2008, p.26);

b. Estabelecendo condições para o contexto criativo (LANDRY apud MERONI, 2007, p.11);

c. Desenvolvendo ferramentas, equipamentos e infraestrutura de apoio para práticas promissoras (MALAGUTI, 2009a, p.33);

d. Utilizando seus conhecimentos e ferramentas específicos para facilitar a convergência em direção às ideias compartilhadas e soluções potenciais (MANZINI, 2008a, p.97).

O foco projetual do Design evolui em direção a uma perspectiva sistêmica, aumentando seu campo de ação. Nesse ponto, como destaca Krucken (2008, p. 26), é fundamental para o designer desenvolver competências para ser um facilitador no processo de inovação, promovendo formas de colaboração e participação ativa: integrar, ativar diálogos, criar conexões - ao mesmo tempo contextualizar e globalizar.

Nessas "redes de ação multidisciplinares" o designer contribui na criação de artefatos e processos de diversas formas, articulando "a infra-estrutura hard, como lugares, concessões culturais, instalações, tecnologia e equipamentos e condições soft como sistemas de rede e contatos entre as pessoas" (LANDRY apud MERONI, 2007, p.11), no sentido de promover estilos de vida e emancipação dos sujeitos, relações cooperativas e harmoniosas voltados à sustentabilidade (MENDES, MEDEIROS e ONO, 2009 , n.p.) e regenerar a qualidade do contexto de vida (MANZINI, 2008, p.47).

Os novos cenários de vida e as possibilidades de soluções sustentáveis baseiamse sobretudo em redes de comunicação e ações colaborativas (MENDES, MEDEIROS e ONO, 2009, n.p.). Mais uma vez, uma competência afim, já que Design é em essência comunicação, incluindo comunicação de valores e identidades culturais (MARZANO, 1993, n.p.).

É gerado um tipo original de redes de Design: "grupos amplos e flexíveis de agentes sociais que criam e desenvolvem colaborativamente soluções sustentáveis" (MANZINI, 2008a, p. 97-). Os designers são parte destas redes de Design emergentes e devem colaborar oferecendo suas competências específicas e alimentar essas redes de Design com seus conhecimentos profissionais, interagindo com outros designers não profissionais em um modelo de parceria (KRUCKEN, 2008, p. 28).

Assim, colocando em ato descontinuidades locais promissoras e participando no desenvolvimento de um bem-estar ativo - em que as capacidades de sensibilidade, competência e espírito de iniciativa tem um importante papel -, o Design pode contribuir para mudanças sistêmicas efetivas (MANZINI, 2008a, p. 36). Em síntese, cabe ao designer participar ativa e positivamente no desenvolvimento de soluções sustentáveis, em diversos campos (MANZINI, 2008a, p. 36-37). Nesse contexto, as práticas de codesign e criação coletiva de estratégias e ferramentas surgem como modos de ação promissores. O papel do design na promoção da cultura de sustentabilidade entre jovens foi aprofundado em estudo realizado por Mouchrek (2014) ${ }^{1}$.

\footnotetext{
1 Pesquisa de mestrado desenvolvida pela pesquisadora Najla Mouchrek junto ao junto ao Programa de Pósgraduação da Universidade do Estado de Minas Gerais, sob orientação da Profa Dra Lia Krucken. (MOUCHREK, 2014)
} 


\section{PROCEDIMENTOS E MÉTODOS: Abordagem aplicada de cocriação em design}

A natureza da presente pesquisa é de ordem qualitativa e utiliza abordagem multimétodos, tendo utilizado uma composição de procedimentos e ferramentas de pesquisa em design.

A pesquisa em Design é fonte fundamental no ciclo de criação e articulação de conhecimento na área, na medida em que oferece fundamento para a prática e para o desenvolvimento de pensamento crítico e reflexão aprofundada (FRIEDMAN, 2000, p. 13). Destaca-se aqui o potencial da pesquisa em Design para: a) abrir investigação em questões ainda não levantadas (FRIEDMAN, 2000, p.25); b) enriquecer as habilidades do designer/estudante/pesquisador em Design em elaborar uma compreensão ampliada e um conhecimento consciente face às questões que se apresentam na atualidade (PIZZOCARO, 2011, p.95).

Acompanhando uma tendência geral de mudança de perspectiva no campo, atualmente apresentam-se vários tipos, caminhos e atividades de pesquisa em Design (BUCHANAN, 2001, p.17). Além dos métodos tradicionais, a pesquisa em Design vem utilizando, cada vez mais, novos métodos desenvolvidos especificamente a partir do pensamento e prática do Design, muitos deles ainda em progresso (PIZZOCARO, 2011, p.90). Entre os métodos em progresso, destacam-se as abordagens de cocriação em Design, que representam procedimentos metodológicos centrais no presente trabalho.

Observa-se que o termo cocriação tem definições muito diferentes, dependendo do contexto em que se insere (NIELSEN, 2010, p.1). Para os fins desse trabalho, considera-se cocriação na perspectiva do Design, sendo portanto sinônimo do termo codesign. O termo denomina um processo que "envolve a criatividade de designers e de pessoas não treinadas em design trabalhando juntos no processo de desenvolvimento em Design" (SANDERS e STAPPERS, 2008, p.1), a participação de vários atores nas decisões chaves do processo de Design.

Trazer a cocriação para a prática em design causará uma série de mudanças no futuro. Mudará a forma de projetar, o que nós projetamos e quem projeta. Isso também afetará as ferramentas e métodos que as novas equipes de codesigners utilizarão.(SANDERS e STAPPERS, 2008, p.12)

Na definição de Kingsley (2009), cocriação / codesign é uma forma de progredir através de um problema ou cenário e é usado, por exemplo, para promover mudanças de comportamento (KINGSLEY, 2009, p.1). Na condução de processos de cocriação, os papeis alteram-se e tornam mais complexos: o usuário / público passa a ser codesigner do processo, os designers/ pesquisadores passam a ser também facilitadores e os designers englobam novas funções, demandando novas habilidades e competências, como indicam os autores a seguir:

O designer / pesquisador fornece ferramentas para a ideação e desenha o processo de inovação. O designer / pesquisador e o usuário colabora com as ferramentas para a ideação. Finalmente, o designer / pesquisador dá forma às ideias (NIELSEN, 2010, p.1). 
Nesse sentido, destaca-se a importância de desenvolver competências e proporcionar oportunidades de experimentação em abordagens de cocriação no ensino de Design. A iniciativa apresentada a seguir está orientada a esses propósitos.

\subsection{Laboratório de Design, Cocriação e Sustentabilidade - ED-UEMG}

A iniciativa foi desenvolvida no contexto da disciplina optativa Inovação aberta, Design e sustentabilidade, coordenada pela Prof. Lia Krucken, com participação de Najla Mouchrek (estágio de docência) e Ana Carolina Ribeiro, junto ao Curso de Graduação em Design da Universidade do Estado de Minas Gerais. O conteúdo e a abordagem metodológica da disciplina foram idealizados e ministrados pelas autoras.

De caráter experimental, a disciplina teve como propósito ampliar a capacidade de intervenção ativa dos futuros designers em contextos de transição rumo à sustentabilidade, estimulando-os a interagir colaborativamente para desenvolver, viabilizar e implementar soluções inovadoras nesse campo.

Foi proposto o desenvolvimento de um projeto aberto, que envolveu e estimulou várias competências de Design, inovação e sustentabilidade, incluindo a utilização de ferramentas de Design, como mapeamento visual, mapas colaborativos, sessões de ideação, desktop research, técnicas de visualização, questionários e enquetes virtuais, prototipagem e imersão com participação do usuário.
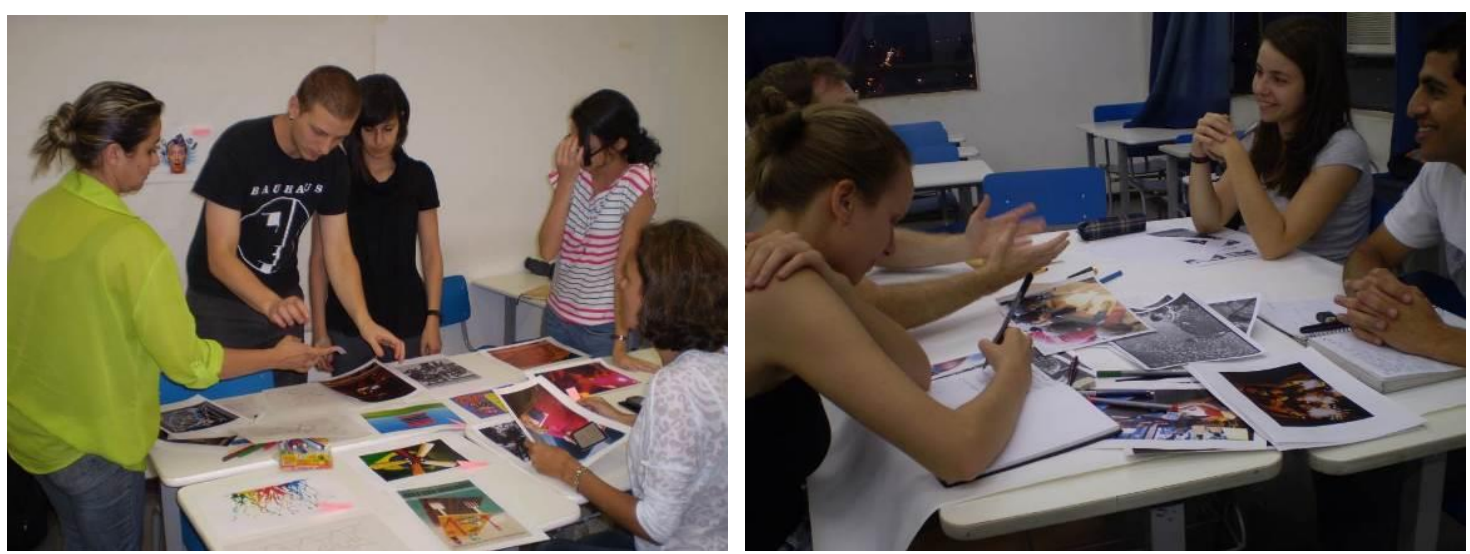

Figura 1 : Laboratório de Design, cocriação e sustentabilidade. Disciplina Inovação aberta, Design e Sustentabilidade (ED-UEMG / 2ำ semestre 2013). Fonte: acervo fotográfico das autoras, 2013.

A princípio, definiu-se como foco projetual: promover a cultura de sustentabilidade junto ao público jovem de 14 a 24 anos. Os alunos da disciplina tinham em média 18 a 24 anos e dessa forma, por constituírem também o públicoalvo, em vários casos eram ao mesmo tempo usuários e designers das soluções propostas. Os estudantes aprenderam a partir de situações reais, buscando meios de compreensão e solução à medida que as questões surgiam.

A abordagem proposta previa uma fase inicial de discussão e amplificação de conceitos e duas fases aplicadas de projeto, consistindo em pesquisa e desenvolvimento de projeto. 


\section{Fase 1 - Levantamentos iniciais e fundamentação teórica (fase conceitual)}

O propósito da fase inicial foi abrir o debate e introduzir os temas a serem explorados na disciplina, ampliar e aprofundar conceitos e construir uma abordagem colaborativa que orientaria as fases subsequentes. Consistiu em:

- Sessões de ideação e construção de mapas visuais coletivos:

a. Concepções de Design / potencialidades e limites

b. Caracterização do público: O que é ser jovem hoje? Qual o espírito desse tempo?

c. Que questões emergem? Como o Design pode intervir sobre elas?

- Discussão e aplicação dos critérios de análise sobre a produção coletiva

- Aulas expositivas e debates:

a. Visões contemporâneas de Design

b. Abordagens de sustentabilidade em projetos de Design.

c. Elementos sobre Pesquisa em Design / abordagens e ferramentas

d. Exemplos e estudos de caso sobre abordagens sistêmicas em Design, Design Estratégico, inovação aberta

Destacam-se os resultados dos mapas coletivos elaborados no início do processo. A atividade propiciou a emergência de várias questões e alimentou um debate ativo entre os estudantes, que demonstraram interesse, vontade de expressar seus pontos de vista e construíram em colaboração um perfil complexo e bastante interessante das questões ligadas à realidade dos jovens. A síntese das questões abordadas nos mapas está na figura 2 , na página a seguir.

\section{Fase 2 - Pesquisa}

A partir dos temas abordados nos mapas e das análises realizadas em conjunto, os estudantes se organizaram em grupos e escolheram temas para elaboração de um projeto. Buscou-se responder às questões: "Quais são as oportunidades ou os problemas percebidos? Como estão relacionados com as dimensões de sustentabilidade?". Foram então direcionadas 4 semanas para pesquisa deste tema, incluindo roteiro e preparação, ida a campo e apresentação da fase inicial de projeto. 


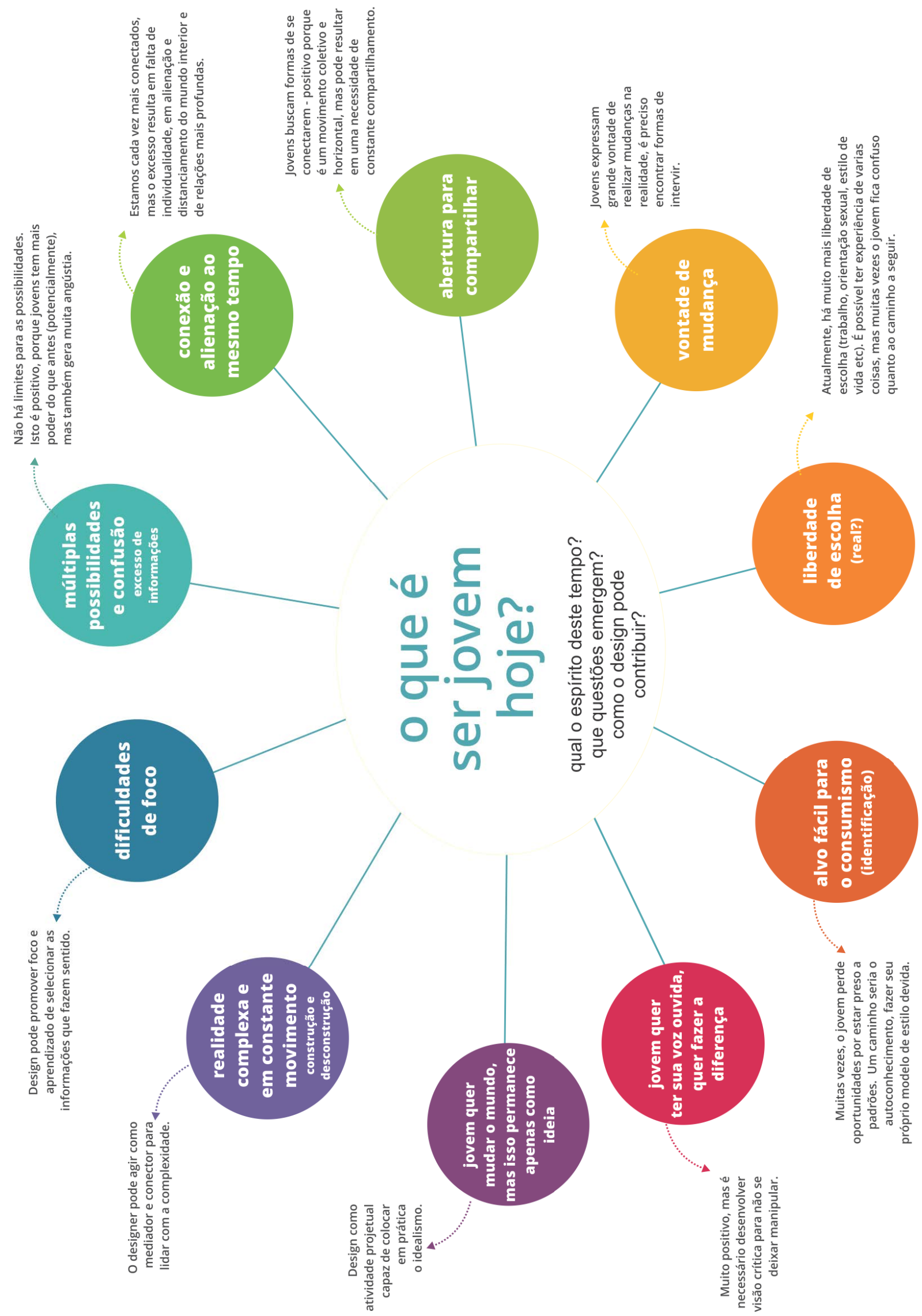

Figura 2 - Síntese dos aspectos relevantes apontados pelos alunos nos mapas visuais e discussões em grupo. Fase 1 - Disciplina Inovação aberta, Design e Sustentabilidade. Fonte: Elaborada pelas autoras a partir dos resultados da pesquisa, 2014. 


\section{Fase 3 - Projeto}

Terminada a fase de pesquisa, os estudantes apresentaram a síntese do andamento do projeto, através de um template (Figura 3). Nessa fase, o objetivo é estimular o desenvolvimento das habilidades de síntese, visualização, familiaridade com desenvolvimento e etapas de projeto e capacidade de organização para a continuação.

\section{Template para apresentação do andamento do projeto}

(fase intermediária)

\begin{tabular}{|c|c|c|c|c|c|}
\hline APRESENTAÇÃO & CONTEXTO & CONCEITO & ANDAMENTO & $\begin{array}{l}\text { POSSIVEIS } \\
\text { RESULTADOS }\end{array}$ & REFERÊNCIAS \\
\hline $\begin{array}{l}\text { Título e subtitulo do } \\
\text { projeto, } 2-4 \\
\text { palavras-chave } \\
\text { (1 imagem) }\end{array}$ & $\begin{array}{l}\text { Descrição do } \\
\text { contexto, incluindo } \\
\text { público, local, } \\
\text { oportunidades e } \\
\text { problemas } \\
\text { detectados } \\
\text { (max. } 200 \text { caracteres } \\
+1 \text { imagem) }\end{array}$ & $\begin{array}{l}\text { Descrição da ideia } \\
\text { central, a proposta } \\
\text { em que o grupo } \\
\text { está trabalhando } \\
\text { (max. } 200 \text { caracteres } \\
+1 \text { imagem) }\end{array}$ & $\begin{array}{l}\text { Descrição do que } \\
\text { foi feito até agora e } \\
\text { as possíveis } \\
\text { ferramentas para } \\
\text { continuação } \\
\text { (max. } 200 \text { caracteres } \\
+1 \text { imagem) }\end{array}$ & $\begin{array}{l}\text { Descrição dos } \\
\text { resultados } \\
\text { projetados } \\
\text { (max. } 200 \text { caracteres } \\
+1 \text { imagem) }\end{array}$ & $\begin{array}{l}\text { Apresentação das } \\
\text { principais referências / } \\
\text { fontes de pesquisa } \\
\text { até agora }\end{array}$ \\
\hline
\end{tabular}

Figura 3 - Modelo para apresentação do andamento do projeto - Fase 2 - Disciplina Inovação aberta, Design e Sustentabilidade (ED-UEMG / 20 semestre 2013). Fonte: KRUCKEN e MOUCHREK (2013)

Após a apresentação e o debate coletivo sobre o projeto e o andamento do trabalho de cada grupo, partiu-se para a fase de execução propriamente dita. Ao final, os grupos tiveram quatro semanas para desenvolverem seus projetos, que deveriam contar com algum tipo de aplicação, ainda que em fase piloto. Como resultado final, os grupos fizeram uma apresentação de 15 minutos, em que descreveram as fases do processo, o produto / intervenção piloto desenvolvido e analisaram o processo como um todo.
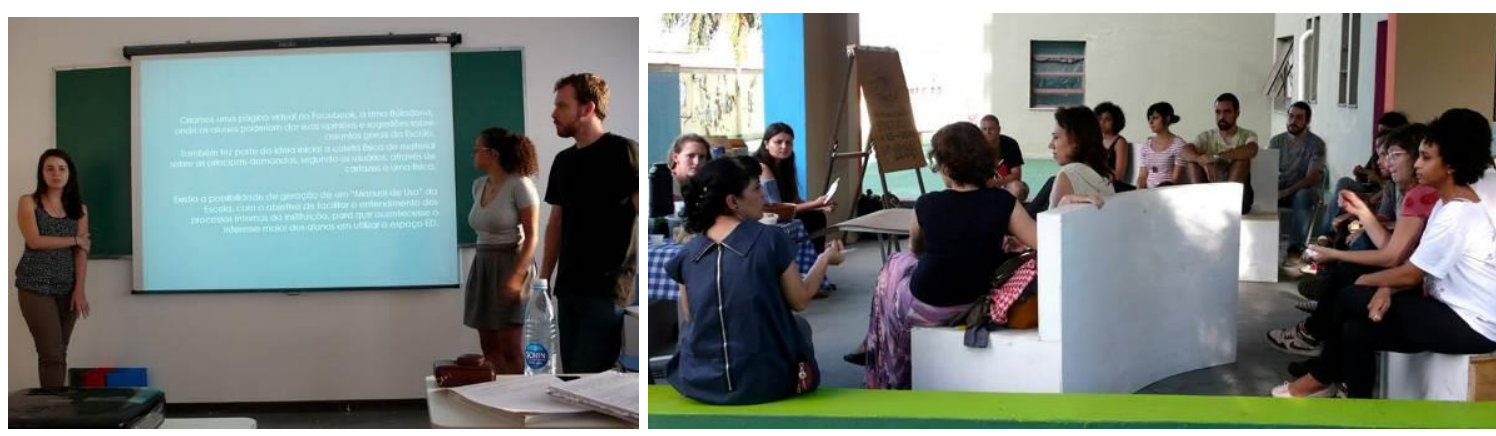

Figura 4: Desenvolvimento e apresentação final de projetos - Fase 3. Disciplina Inovação aberta, Design e Sustentabilidade (ED-UEMG / 2o semestre 2013). Fonte: Acervo fotográfico das autoras, 2013. 
Projeto 1 - CAFE - Cocriar, Apropriar, Financiar, Experimentar o espaço público

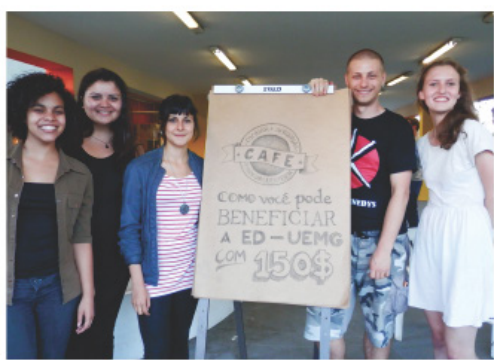

Projeto 2 - URNA BOLADONA

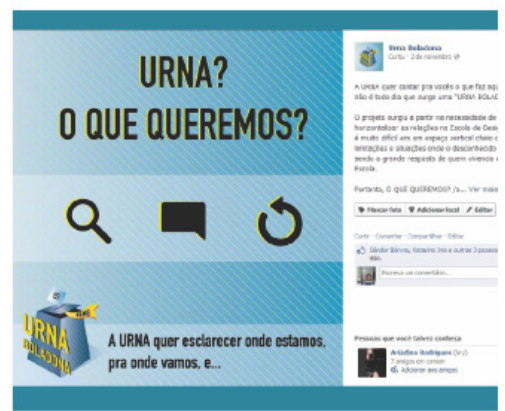

Questão: Espaço público | Incentivar a

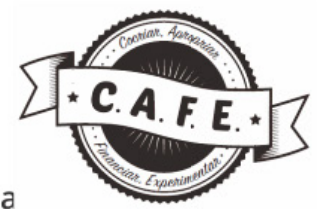
apropriação colaborativa comunitária no espaço público

Solução: Projeto para o espaço público, discutido em público, escolhido pelo público. Realização de evento aberto ao público, com recursos de microfinanciamento coletivo para realizar projetos no contexto local (ED-UEMG)

\section{Projeto 3 - 0 que o designer faz? Construindo um futuro profissional sustentável}

Questão: Relação do jovem estudante da Oi Kabum! com futuro profissional | Orientação e escolhas

Solução: Gerar a reflexão no jovem sobre futuro profissional e mostrar qual seria a abordagem do Design neste contexto | Elaboração de um vídeo a ser compartilhado com jovens da Oi Kabum!

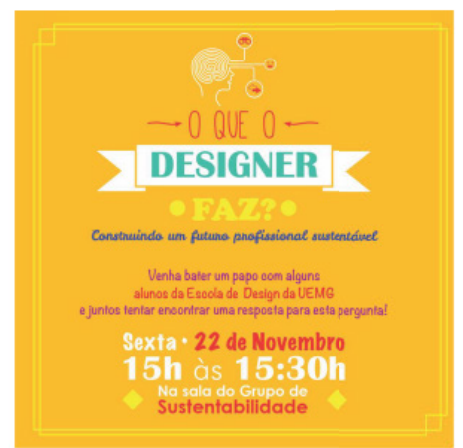

\section{Projeto 4 - Proposição de novo sistema de ocupação do hall - ED-UEMG}
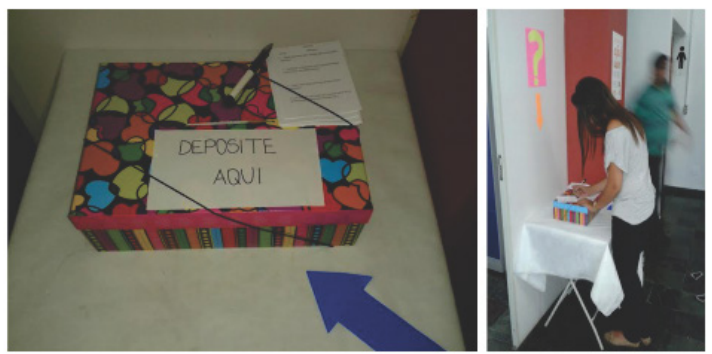

Questão: Criar espaços de integração dos cursos da ED-UEMG em ambientes sub aproveitados (hall)

Solução: Pesquisa de conhecimento de eventos e ocupação do hall. Propor a exposição de trabalhos de forma unificada, integrada de modo a proporcionar a valorização dos cursos.

Figura 5: Síntese dos projetos desenvolvidos pelos alunos - Disciplina Inovação aberta, Design e Sustentabilidade (ED-UEMG / 2o semestre 2013). Fonte: Quadro elaborado pelas autoras, 2014. 


\section{CONCLUSÃO}

O Laboratório de Design, Cocriação e Sustentabilidade promoveu resultados interessantes e demonstrou-se uma iniciativa promissora em direção aos propósitos dessa pesquisa, na medida em que resultou na produção de resultados coletivos concretos, a partir da junção dinâmica de diversas competências e perspectivas.

A abordagem propiciou o desenvolvimento de competências como análise de contexto, proposição de focos para intervenção, pesquisa e seleção de informações e de formas de intervenção, conhecimento e seleção de ferramentas de Design, síntese, visualização, familiaridade com desenvolvimento e etapas de projeto e capacidade de organização e comunicação.

Alguns aspectos importantes merecem ser destacados em relação às dinâmicas propostas pelos estudantes, que incluem:

a. o uso ativo de plataformas de relação social como ferramenta para comunicação e interação de forma inovadora;

b. o uso de referências alternativas na busca de conteúdos (ex. vídeos, filmes, outras iniciativas);

c. a percepção do conceito de sustentabilidade em relação ao momento de vida e ao contexto em que vivem os jovens hoje;

d. a intenção de promover processos democráticos para que os jovens possam manifestar suas aspirações e transformá-las em ação com apoio das ferramentas e métodos de Design.

Conclui-se que, no contexto das iniciativas motivadas e conduzidas pelo Design, as abordagens participativas e baseadas na cocriação oferecem excelentes oportunidades para promover cultura de sustentabilidade junto aos jovens (especialmente jovens estudantes de Design), na medida em que:

a. favorecem o desenvolvimento da capacidade reflexiva e da habilidade de analisar problemas complexos e buscar soluções diferenciadas;

b. proporcionam campos de experimentação em que o jovem explora a possibilidade de criar soluções a partir de seus próprios recursos e motivações de ação;

c. oferecem uma gama de ferramentas e formas de intervenção, que os jovens aprendem colaborativamente a selecionar e aplicar;

d. criam possibilidades de desenvolvimento de projetos concretos e voltados à ação;

e. o impacto das ações gera um mecanismo de feedback e confirmação da comunidade de referência, o que nutre e estimula novos ciclos de projeto e ação aplicada.

Ao final, confirmaram-se na prática várias das acepções levantadas no referencial teórico e abriram-se novas percepções. Entre os aspectos que se destacam como resultado dessa análise, apontamos as constatações de que os temas ligados à sustentabilidade que despertam interesse e motivam ações são aqueles ligados à realidade atual do jovem e que estes respondem positivamente quando encontram contextos que favoreçam a organização de ideias e recursos e a condução de processos projetuais, permitindo direcionar suas aspirações e pontos de vista em direção à realização prática. 
Finalmente, conclui-se que o aprendizado de condução de pesquisa e projeto, além de desenvolver competências técnicas e capacidade de análise e realização, também promove auto-estima e nutre processos de autonomia e empoderamento entre os jovens.

\section{Agradecimento}

Agradecemos à Universidade do Estado de Minas Gerais pelo apoio institucional. Agradecemos também à designer Ana Carolina Ribeiro e aos alunos da disciplina "Inovação aberta, Design e Sustentabilidade" (ED/UEMG) no segundo semestre de 2013 e a todos que contribuíram para este trabalho.

\section{REFERÊNCIAS}

BUCHANAN, Richard. Design research and the new learning. Design Issues, MIT Press, Cambridge, v. 17, n. 4, p. 3-23, 2001.

CARDOSO, Rafael. Design para um mundo complexo. São Paulo: Cosac Naify, 2012.

FONTOURA, Antônio Martiniano. EdaDe: a educação de crianças e jovens através do Design. Tese (Doutorado em Engenharia de Produção) Programa de Pós-graduação em Engenharia de Produção. Universidade Federal de Santa Catarina. Florianópolis, 2002.

FRANZATO, Carlo. O design estratégico no diálogo entre cultura de projeto e cultura de empresa. Strategic Design Research Journal, v. 3, n. 3, p. 89-96, 2010.

FRIEDMAN, K. Creating design knowledge: from research into practice. In: IDATER 2000 CONFERENCE, 2000, Proceedings...Loughborough: Loughborough University, 2000.

KINGSLEY, Christine. Co-Design and the use of Stories to Enable Empathy. In: European Academy of Design Conference, The Robert Gordon University, Aberdeen, Scotland. 2009.

KRUCKEN, Lia. Competências para o Design na sociedade contemporânea. In: De Moraes, D.; Krucken, L.. (Org.). Design e Transversalidade. 1 ed. Belo Horizonte: Santa Clara, 2008, v. 1.

Studio Nobel, 2009.

Design e Território - Valorização de identidades e produtos locais.

KRUCKEN, Lia, BOSCHI, Marco Túlio. Guia para apresentação dos projetos de design estratégico. Notas de aula. Disciplina "Cadeia de valor e valorização de recursos locais", Universidade do Estado de Minas Gerais, Belo Horizonte, Maio de 2013.

KRUCKEN, Lia, MOUCHREK, Najla. Modelo para apresentação do andamento do projeto. Notas de aula. Disciplina "Inovação aberta, Design e Sustentabilidade", Universidade do Estado de Minas Gerais, Belo Horizonte, Setembro de 2013.

LACLAU, Ernest. New Reflections on the Resolution of our Time. Londres: Verso, 1990. MALAGUTI, Cyntia Santos. Design e valores materializados - cultura, ética e sustentabilidade. In: De Moraes, Dijon; Krucken, Lia. (Org.). Cadernos de Estudos Avançados em Design Sustentabilidade I. 1 ed. Barbacena: Editora da Universidade do Estado de Minas Gerais, 2009a, v. 1. 
MANZINI, Ezio. A laboratory of ideas. Diffuse creativity and new ways of doing. In: MERONI, Anna. Creative communities: People inventing sustainable ways of living. Milano: Edizioni POLI.Design, 2007.

Design para a inovação social e sustentabilidade: comunidades criativas organizações colaborativas e novas redes projetuais. Ezio Manzini; Rio de Janeiro: E-papers, 2008a. (Cadernos do Grupo de Altos Estudos; v. 1)

Introdução. In: Shaping the Global Design Agenda - an International Conference on Design Policy. 6-7 November 2008b. Torino, Italy.

Notas de aula. Curitiba, 2012.

MARGOLIN, Victor. Design, the Future and the Human Spirit. In: Design Issues: Volume 23, Number 3 Summer 2007

MARZANO, Stefano. Chocolate for breakfast. Key note address to the 18th ICSID Congress, Glasgow, 1993. ICSID News 6/93. International Council of Societies of Industrial Design, Helsinki, 1993.

MCCARTHY, Iseult; GRENVILLE, Gary. Design in education, a discussion paper. Dublin: National Council for Curriculum and Assessment, 1997.

MENDES, Mariuze D.; MEDEIROS, Jusmeri; ONO, Maristela M. Estilos de vida e mediação de Design na construção de cenários sustentáveis. In: II Simpósio Brasileiro de Design Sustentável - 2009. Anais. Curitiba: UFPR, v. 1, 2009.

MERONI, Anna. Creative communities: People inventing sustainable ways of living. Milano: Edizioni POLI.Design, 2007.

MOUCHREK, Najla. M. Estratégias e competências de Design para promover a cultura de sustentabilidade entre jovens. 2014. 149 f. Dissertação (Mestrado) - Escola de Design, Programa de Pós-Graduação em Design da Universidade do Estado de Minas Gerais, Belo Horizonte, 2014.

MOURA, Catarina. O desígnio do design. In: Anais do 40 Congresso da Associação Portuguesa de Ciências da Comunicação-4ㅇ SOPCOM. Aveiro. 2005.

NIELSEN, Lene. Personas in co-creation and co-design. Proceedings of the 11th Human-Computer Interaction Research Symposium (DHRS2011), pp. 38-40. 2011.

PIZZOCARO, Silvia. Passos iniciais para métodos de pesquisa. In: De Moraes, Dijon, Dias, Regina A.; BOM CONSELHO, Rosemary (org.) Coleção Cadernos de Estudos Avançados em Design, Belo Horizonte: EdUEMG, 2011.

SANDERS, Elizabeth.; STAPPERS, Pieter. Co-creation and the new landscape of design. Disponível em: http://www.maketools.com/articles-papers/CoCreation Sanders Stappers 08 preprint.pdf. Acesso em 14 de abril de 2013.

SIMON, Herbert. The sciences of the artificial, 2nd ed, MIT Press, Cambridge, Massachusetts, 1982. 